\title{
Multisystem Inflammatory Syndrome in Children; an Emerging Global Threat - A Review
}

\author{
AR Shabaraya ${ }^{1}$, Archana KU ${ }^{2}$ \\ ${ }^{1}$ Professor \& Head, ${ }^{2}$ Student Pharm D, \\ Department of Pharmacy Practice, Srinivas College of Pharmacy, Valachil, Mangalore, Karnataka-574143 \\ Corresponding Author: Archana K U
}

\begin{abstract}
MIS C (Multisystem Inflammatory Syndrome in Children) is a disease related to post COVID19 sequelae. Differential diagnosis includes Kawasaki disease, Bacterial sepsis, toxic shock syndrome, Appendicitis, Macrophage activation syndrome. Clinical Presentations include high grade fever, rashes, Gastrointestinal symptoms like (abdominal pain, vomiting, diarrhea), hypotension and shock. The pathogenesis of MIS-C is unknown, and a postinfective etiology has been hypothetical but unproven. Antibodies to SARS-CoV-2 appear in the second week following infection, although their existence does not suggest infection resolution. Laboratory markers of inflammation, such as CRP, are elevated. IVIG, Glucocorticoids such as methyl prednisolone, Antibiotics, thromboprophylaxis with Light Molecular Weight Heparin are the management options. Since the available information doesn't allow to formulate well-established guidelines or recommendations for MIS-C treatment, and therefore the long-term sequelae of the illness aren't yet known.
\end{abstract}

Keywords: MIS C, IVIG, Kawasaki disease

\section{INTRODUCTION}

According to current data there are 3,07,95, 716 SARS Covid 19 active cases in india and 4,07,145 deaths were reported ${ }^{[3]}$. MIS $\mathrm{C}$ is a disease associated with post COVID 19 sequelae. Differential diagnosis includes Kawasaki disease, Bacterial sepsis, Toxic shock syndrome, Appendicitis, Macrophage activation syndrome. Clinical Presentations include high grade fever, rashes, Gastrointestinal symptoms such as (abdominal pain, vomiting, diarrhea), hypotension and shock [1]. On April 25, 2020, the United Kingdom's National Health Service alerted physicians of a newly recognized syndrome with severe multisystem inflammation in children with clinical features similar to those found in Kawasaki disease and toxic shock syndrome ${ }^{[2]}$. The new illness was temporally linked to COVID-19, with symptoms appearing 3-4 weeks after an increase in COVID-19 occurrence in a specific geographic area. Additional cases of children with a hyper inflammatory syndrome involving several systems were reported in subsequent publications from different European nations and the United States ${ }^{[5]}$.

\section{DEFINITION}

According to $\mathrm{CDC}$, the case definition for MIS $\mathrm{C}$ is a person younger than 21 years of age with fever $\left(\geq 38.0^{\circ} \mathrm{C}\right.$ for $\geq 24$ hours), signs of inflammation in the laboratory(increased C-reactive protein (CRP), erythrocyte sedimentation rate (ESR), fibrinogen, procalcitonin, d-dimer, ferritin, lactic acid dehydrogenase (LDH), interleukin 6 (IL-6), elevated neutrophils, reduced lymphocytes and low albumin)and signs of clinically serious illness requiring hospitalization with multisystem organ involved $^{[4]}$.

\section{Kawasaki Disease}

Kawasaki disease (KD), also known as Kawasaki syndrome, is a febrile sickness with unknown etiology that mostly affects 
children under the age of five. Clinical signs include fever, rash, swelling of the hands and feet, irritation and redness of the whites of the eyes, swollen lymph glands in the neck, and irritation and inflammation of the mouth, lips, and throat $^{[9]}$. Laboratory markers of inflammation, such as CRP, are elevated, similar to MIS-C. Patients with KD exhibit leukocytosis with neutrophil predominance and thrombocytosis, which are slightly different hematologic disorders. Thrombocytopenia has been reported in KD patients, however it is uncommon. The cardiac findings in MIS-C differ from those in KD because MIS-C patients are substantially more likely to have cardiac dysfunction and hypotension than coronary artery anomalies.

\section{Toxic shock syndrome}

Toxic shock syndrome (TSS) is a life-threatening condition marked by fever, hypotension, a sunburn-like rash, and endorgan destruction. TSS was once linked to the use of high-absorbency tampons by menstruation women; however these were finally phased out of the market. Since then, it's been increasingly crucial to consider non-menstrual instances. TSS is thought to affect 0.8 to 3.4 per 100,000 in the United States ${ }^{[10]}$.

\section{CLINICAL FEATURES}

MIS C patients present with symptoms similar to Kawasaki disease like symptoms such as Fever, Conjunctivitis, rash, myalgia, stomatitis, lymphadenopathy, extensively swelling with erythema.

- Gastrointestinal symptoms similar to viral gastroenteritis which include nausea, vomiting, abdominal pain, diarrhea elevated AST/ALT ${ }^{[6]}$.

- Kawasaki disease like features were seen in many patients such as skin rash, oral mucosal changes such red lips, strawberry like tongue.

- Cardiovascular abnormalities such myocardial dysfunction, elevated
proBNP and Troponin, coronary aneurysm, hypoperfusion, hypotension Tachycardia

- Respiratory symptoms such as cough, tachypnea, chest congestion, chest infiltrates ${ }^{[7],[8]}$.

\section{PATHOPHYSIOLOGY}

The pathogenesis of MIS-C is unknown, and a post infective etiology has been hypothetical but unproven. Antibodies to SARS-CoV-2 appear in the second week following infection, although their existence does not suggest infection resolution. In comparison to adults with severe COVID19 causing acute respiratory distress syndrome (ARDS) and adults who recovered from mild disease, a recent study found inefficient and reduced neutralising antibody activity against SARS-CoV-2 in patients with MIS-C, implying a reduced protective serological response ${ }^{[11]}$. The virus is rarely found in the respiratory system of MIS-C patients, but other organs, such as the gastrointestinal tract, have yet to be studied $^{[12]}$.

Although the presence of SARSCoV-2-specific $\mathrm{T}$ cells in the peripheral blood of recovered and COVID-ARDS adult patients has recently been reported, no such reports have yet been reported in children, and the biological significance of SARS-CoV-2-reactive $\mathrm{T}$ cells, whether protective or even detrimental, is still unknown $^{[13]}$.

It's also been suggested that the SARS-CoV-2 Spike protein shape has a direct effect on immunological activation. Indeed, new evidence suggests that the SARS-CoV-2 Spike protein has a superantigen-like domain with sequence and structural similarities to Staphylococcal enterotoxin B, which could be responsible for the hyperinflammation seen in MIS-C and adults with severe COVID-19 and

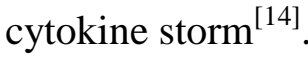




\section{DIAGNOSIS}

\begin{tabular}{|c|c|}
\hline Laboratory Investigations & $\begin{array}{l}\text { - } \quad \text { Complete blood count: leukocytosis and lymphopenia can be seen. } \\
\text { - } \quad \text { CRP: CRP elevation } \\
\text { - Coagulation: Hyperfibrinogenemia is typical, PT and PTT should be monitored to investigate a } \\
\text { prothrombotic state. In case D-dimer is measured, high levels should be interpreted as } \\
\text { potentially related to the hyperinflammatory state. } \\
\text { - } \quad \text { Electrolytes: Hyponatremia may be seen. } \\
\text { - Liver function tests: MIS-C cases with gallbladder hydrops (that may cause } \\
\text { hyperbilirubinemia) have been described. } \\
\text { Kidney function tests: MIS-C cases with acute kidney injury have been observed. } \\
\text { Blood gas analysis: To assess gas exchange and the presence of metabolic acidosis. High } \\
\text { lactates have been described in MIS-C patients without evidence of sepsis. }\end{array}$ \\
\hline & $\begin{array}{l}\text { - } \quad \text { Cultures of blood, urine, and faeces } \\
\text { EBV, Mycoplasma Pneumoniae, Coxackievirus, Echovirus, Adenovirus, Influenza, and VRS } \\
\text { serologies When serologies are positive, PCR testing should be obtained as soon as possible. }\end{array}$ \\
\hline $\begin{array}{l}\text { Performed in case of } \\
\text { Hyperinflammatory state in } \\
\text { laboratory investigations }\end{array}$ & $\begin{array}{ll}\text { - } & \text { Peripheral smear } \\
\text { - } & \text { Triglycerides, Total protein, Total Albumin levels } \\
\text { - } & \text { CPK, LDH } \\
\text { - } & \text { Troponins and NTpro-BNP } \\
\end{array}$ \\
\hline Imaging & $\begin{array}{l}\text { - EKG + Echocardiogram: to look for evidence of myocarditis, valvular insufficiency, } \\
\text { pericarditis, cardiac tamponade, and coronary abnormalities (if cardiac enzymes are elevated or } \\
\text { if clinical suspicion exists). In the event of a cardiac arrest, an echocardiogram may be used to } \\
\text { rule out dehydration. } \\
\text { - } \quad \text { Chest X-RAY } \\
\text { - }\end{array}$ \\
\hline
\end{tabular}

\section{TREATMENT}

The goal of the treatment may vary consistent with the patient. The treatment may depend on the clinical presentations of the patient. Medications given below are that the common treatment approach observed in several studies.

\section{IVIG}

$2 \mathrm{~g} / \mathrm{kg}$ IV (up to $70-80 \mathrm{~g}$ ) to be administered over a minimum of $12 \mathrm{~h}$ in patients with heart failure immunoglobulins should be administered over a minimum of $16 \mathrm{~h}$ or, alternatively, the whole dose should be splitted in two infusions $12 \mathrm{~h}$ apart. A second dose of immunoglobulins should be considered just in case of inadequate response ${ }^{[19]}$.

\section{GLUCOCORTICOIDS}

To be administered with IVIG upfront just in case of heart involvement, severe disease, impendings HLH or toxic shock syndrome.

1. Methylprednisolone $1 \mathrm{mg} / \mathrm{kg}$ BID IV

2. Methylprednisolone $30 \mathrm{mg} / \mathrm{kg}$ (max $1 \mathrm{~g}$ ) IV pulse q1d for 1-3 days, followed by Methylprednisolone i.v./Prednisone orally, supported the severity of clinical/laboratory features
3. Consider Dexamethasone $10 \mathrm{mg} / \mathrm{m} 2 \mathrm{q} 1 \mathrm{~d}$ just in case of sHLH or CNS involvement

i or ii should be chosen counting on disease severity, supported clinical/ laboratory features. Methylprednisolone pulses are recommended just in case of sHLH diagnosis/suspicion.

\section{ALTENATIVETREATMENTOPTIONS}

Large-spectrum antibiotics: while expecting microbiology tests

Acetylsalicylic acid: $5 \mathrm{mg} / \mathrm{kg}$ for a minimum of 6-8 wks. Just in case coronary abnormalities are found, ask AHA recommendations for Kawasaki Disease ${ }^{[16]}$.

Thromboprophylaxis with LMWH: Since adults with COVID-19 are at high risk of thromboembolism, and given the high inflammatory state of youngsters with MIS$\mathrm{C}$, it appears reasonable to start out prophylaxis with LMWH. As per ISTH recommendations ${ }^{[17]}$, risk stratification should be done supported D-Dimer and other known pro-thrombotic factors. Just in case of D-Dimer $>5 \mathrm{X}$ normal values and/or presence of other known pro-thrombotic factors, Enoxaparin100UI/kg BID should be administered. Eculizumab: just in case of acute renal failure and evidence of 
microangiopathy, consider treatment with eculizumab ${ }^{[18]}$.

\section{CONCLUSION}

The clinical features of multisystem inflammatory syndrome are similar to that of Kawasaki disease. Elucidating the pathogenesis of MIS-C is going to be critical to tell rational management strategies and possible preemptive measures. Genetic studies are going to be vital to our understanding of why some children with SARS-CoV-2 infection ultimately develop MIS-C. Given the frequent overlap of clinical manifestations between MIS-C and Kawasaki disease, patients with the hyper inflammatory syndrome have generally been treated with the therapeutic protocols utilized in Kawasaki disease. Since the available information doesn't allow to formulate wellestablished guidelines or recommendations for MIS-C treatment, and therefore the long-term sequelae of the illness aren't yet known.

\section{Acknowledgement: None}

\section{Conflict of Interest: None}

\section{Source of Funding: None}

\section{Ethical Approval: Not required}

\section{REFERENCES}

1. Simon H, Sakano TM, Rodrigues RM, Eisencraft AP, Carvalho VE, Schvartsman C, Reis AG. Multisystem inflammatory syndrome associated with COVID-19 from the pediatric emergency physician's point of view is. Jornal de pediatria. 2021 Apr 19;97: 140-59.

2. Feldstein LR, Rose EB, Horwitz SM et al, Multisystem Inflammatory Syndrome in U.S. Children and Adolescents. N Engl J Med 2020; 383:334-346. DOI: 10.1056/NEJMoa2021680

3. \#IndiaFightsCorona COVID-19 [Internet]. MyGov.in. 2021 [cited 10 July 2021]. Available from:
4. Centers for Disease Control and Prevention. 2021. Multisystem Inflammatory Syndrome (MIS). [online] Available at: <https://www.cdc.gov/mis/hcp/index.html> [Accessed 6 June 2021].

5. Abrams JY, Godfred-Cato SE, Oster ME, Chow EJ, Koumans EH, Bryant B, Leung JW, Belay ED. Multisystem inflammatory syndrome in children associated with severe acute respiratory syndrome coronavirus 2: a systematic review. The Journal of pediatrics. 2020 Nov 1;226:45-54.

6. Belhadjer Z, Méot M, Bajolle F, Khraiche D, Legendre A, Abakka S, Auriau J, Grimaud M, Oualha M, Beghetti M, Wacker J. Acute heart failure in multisystem inflammatory syndrome in children in the context of global SARS-CoV-2 pandemic. Circulation. 2020 Aug 4;142(5):429-36.

7. Feldstein LR, Rose EB, Horwitz SM, Collins JP, Newhams MM, Son MB, Newburger JW, Kleinman LC, Heidemann SM, Martin AA, Singh AR. Multisystem inflammatory syndrome in US children and adolescents. New England Journal of Medicine. 2020 Jul 23;383(4):334-46.

8. Dufort EM, Koumans EH, Chow EJ, Rosenthal EM, Muse A, Rowlands J, Barranco MA, Maxted AM, Rosenberg ES, Easton D, Udo T. Multisystem inflammatory syndrome in children in New York State. New England Journal of Medicine. 2020 Jul 23;383(4):347-58.

9. Case Definition |Kawasaki Disease |CDC . Cdc.gov. 2021 [cited 10 July 2021]. Available from: https://www.cdc.gov/kawasaki/casedefinition.html

10. Ross A, Shoff HW. Toxic shock syndrome. In: StatPearls [Internet]. Treasure Island (FL): StatPearls Publishing; 2021 Jan. 2020 Nov 19.

11. Weisberg SP, et al. Antibody responses to SARS-CoV2 are distinct in children with MIS-C compared to adults with COVID-19. Available Form: medRxiv. https://doi.org/10.1101/2020.07.12.2015106 8 Published July 14, 2020. Accessed 2021 July 14

12. Wölfel R, Corman VM, Guggemos W, Seilmaier M, Zange S, Müller MA, Niemeyer D, Jones TC, Vollmar P, Rothe C, Hoelscher M. Virological assessment of hospitalized patients with COVID-2019. Nature. 2020 May;581(7809):465-9. 
13. Sette A, Crotty S. Pre-existing immunity to SARS-CoV-2: the knowns and unknowns. Nature Reviews Immunology. 2020 Aug;20 (8):457-8.

14. Cheng $\mathrm{MH}$, et al. Superantigenic character of an insert unique to SARS-CoV-2 spike supported by skewed TCR repertoire in patients with hyperinflammation.Sep 2020.

15. Ravelli A, Minoia F, Davì S, Horne A, Bovis F, Pistorio A, Aricò M, Avcin T, Behrens EM, De Benedetti F, Filipovic L. 2016 classification criteria for macrophage activation syndrome complicating systemic juvenile idiopathic arthritis: a European League Against Rheumatism/American College of Rheumatology/Paediatric Rheumatology International Trials Organisation collaborative initiative. Annals of the Rheumatic Diseases. 2016 Mar 1;75 (3):481-9.

16. McCrindle BW, Rowley AH, Newburger JW, Burns JC, Bolger AF, Gewitz M, Baker AL, Jackson MA, Takahashi M, Shah PB, Kobayashi T. Diagnosis, treatment, and long-term management of Kawasaki disease: a scientific statement for health professionals from the American Heart Association. Circulation. 2017 Apr 25;135 (17):e927-99.
17. Goldenberg NA, Sochet A, Albisetti M, Biss T, Bonduel M, Jaffray J, MacLaren G, Monagle P, O'Brien S, Raffini L, Revel-Vilk S. Consensus-based clinical recommendations and research priorities for anticoagulant thromboprophylaxis in children hospitalized for COVID-19-related illness. Journal of Thrombosis and Haemostasis. 2020 Nov;18(11):3099-105.

18. Mahajan R, Lipton M, Broglie L, Jain NG, Uy NS. Eculizumab treatment for renal failure in a pediatric patient with COVID19. Journal of Nephrology. 2020 Dec;33(6): 1373-6.

19. McMurray JC, May JW, Cunningham MW, Jones OY. Multisystem inflammatory syndrome in children (MIS-C), a post-viral myocarditis and systemic vasculitis-a critical review of its pathogenesis and treatment. Frontiers in Pediatrics. 2020 Dec $16 ; 8: 871$.

How to cite this article: A R Shabaraya, Archana K U. Multisystem inflammatory syndrome in children; an emerging global threat-a review. International Journal of Research and Review. 2021; 8(7): 481-485. DOI: https://doi.org/10.52403/ijrr.20210768 